\title{
PENGARUH DIMENSI STAFFING TERHADAP INSIDEN KESELAMATAN PASIEN BERDASARKAN AGENCY FOR HEALTCARE RESEARCH AND QUALITY (AHRQ) DI RSU HAJI SURABAYA
}

THE INFLUENCE OF STAFFING DIMENSION ON PATIENT SAFETY INCIDENTS BASE ON AGENCY FOR HEALTCARE RESEARCH AND QUALITY (AHRQ) IN RSU HAJI SURABAYA

\author{
Setya Budi Rahayu \\ Ikatan Bidan Indonesia (IBI) Sidoarjo \\ E-mail: setya.budi.rahayu-2014@fkm.unair.ac.id
}

\begin{abstract}
The incidence of patient safety is an indicator that can be used to describe the quality of hospital services. Based on data obtained from reports IKP in RSU Haji Surabaya in 2015 is known to have occurred 40 patient safety incidents. This research to analyze the influence of staffing dimension base on AHRQ with patient safety incidents in service work unit RSU Haji Surabaya using simple linier regression test. The results showed from the 38 unit service work RSU Haji Surabaya there are 18 units (47,36\%) categorized as a strong staffing dimension with a positive response $\geq 75 \%, 16$ units $(42,11 \%)$ the medium categorized staffing dimension with a positive response from $75 \%-50 \%$ and 4 units (10,53\%) the weak categorized staffing dimension with a positive response $<50 \%$. And according to a report IKP RSU Haji Surabaya January - October 2016 there were 22 incidents of patient safety that consists of $5 \mathrm{KTD}, 3 \mathrm{KNC}$ and $14 \mathrm{KTC}$. In this research can be concluded that there is no significant relationship between staffing dimension with patient safety incidents in service work unit RSU Haji Surabaya. This can be due to by various factors that occurs in the system.
\end{abstract}

Keywords: $A H R Q$, Patient Safety Incident, Staffing Dimension

\section{PENDAHULUAN}

Keselamatan pasien merupakan pencegahan cedera terhadap pasien. Pencegahan cedera didefinisikan bebas dari bahaya yang terjadi dengan tidak sengaja atau dapat dicegah sebagai hasil perawatan medis. Praktek keselamatan pasien adalah mengurangi risiko kejadian yang tidak diinginkan yang berhubungan dengan paparan terhadap lingkungan diagnosis atau kondisi perawatan medis (Hughes, 2008).

Berkaitan dengan program keselamatan pasien di Rumah Sakit Umum Haji Surabaya, diperoleh data mengenai insiden keselamatan pasien yang terjadi dalam tahun 2013 - 2015 di RSU Haji Surabaya ditunjukkan pada tabel 1

Berdasarkan tabel 1 dapat dilihat bahwa secara umum insiden keselamatan pasien dari tahun 2013 - 2015 terjadi penurunan, tetapi pada Kejadian Tidak Diharapkan (KTD) pada tahun 2014
- 2015 terjadi peningkatan dari jumlah pada tahun 2014 sebanyak 2 kejadian menjadi 10 kejadian pada tahun 2015 .

Tabel 1. Insiden Keselamatan Pasien di RSU Haji Surabaya Tahun 2013 - 2015

\begin{tabular}{cccc}
\hline Jenis & \multicolumn{3}{c}{ Jumlah } \\
\cline { 2 - 4 } \multicolumn{1}{c}{ IKP } & $\mathbf{2 0 1 3}$ & $\mathbf{2 0 1 4}$ & $\mathbf{2 0 1 5}$ \\
\hline KTC & 27 & 22 & 12 \\
KTD & 32 & 2 & 10 \\
KNC & 40 & 33 & 18 \\
KPC & 0 & 3 & 0 \\
\hline Total & $\mathbf{9 9}$ & $\mathbf{6 0}$ & $\mathbf{4 0}$
\end{tabular}

Sumber: Laporan IKP RSU Haji Tahun 2013 - 2015

Kenaikan angka insiden yang terjadi bertentangan dengan keadaan normatif dalam Panduan Keselamatan Rumah Sakit yang bertujuan untuk menurunkan KTD di rumah sakit (Depkes RI, 2008). Berdasarkan Keputusan Menteri Kesehatan Nomor 129 Tahun 2008 tentang Standar Pelayanan Minimal Rumah Sakit disebutkan bahwa standar pelayanan minimal pada dimensi mutu keselamatan pasien adalah $100 \%$, sehingga mempunyai arti 
bahwa insiden yang berkaitan dengan keselamatan pasien harus zero defect (kejadian 0\%).

Tahun 2013 telah dilakukan penelitian oleh Iswatun mahasiswa program pasca sarjana Universitas Sebelas Maret Surakarta dengan judul penelitian "Hubungan Beban Kerja Dan Motivasi Kerja Dengan Kinerja Perawat Di RSUD Dr. Soegiri Lamongan”. Di dapatkan faktor-faktor yang mempengaruhi kinerja perawat adalah beban kerja, motivasi, gaji, variasi kerja, pengawas/supervisor, promosi dan kondisi kerja.

Berdasarkan hasil penelitian budaya keselamatan pasien yang dilakukan pada bulan November - Desember 2016 di RSU Haji Surabaya, dapat diketahui bahwa staffing merupakan dimensi berkategori lemah. Elemen SDM dalam organisasi pelayanan kesehatan mempunyai peran sentral dalam orientasi pencapaian tujuan organisasi. Manajemen SDM sangat penting sebab organisasi/perusahaan yang mengimplementasikan secara benar ternyata telah berhasil mewujudkan eksistensinya secara kompetitif dan mencapai sukses seperti yang diinginkan (Nawawi, 2008).

Uraian menunjukkan perlunya dilakukan kajian mengenai pengaruh dimensi staffing terhadap insiden keselamatan pasien di Rumah Sakit Umum Haji Surabaya.

\section{PUSTAKA}

\section{Keselamatan Pasien}

Keselamatan pasien (patient safety) berdasarkan PMK RI Nomor 1691 tahun 2011 adalah suatu di rumah sakit yang bertujuan membuat asuhan pasien lebih aman. Sistem tersebut meliputi assesemen risiko, identifikasi dan pengelolaan hal yang berhubungan dengan risiko pasien, pelaporan dan analisis insiden, kemampuan belajar dari insiden dan tindak lanjutnya serta implementasi solusi untuk meminimalkan timbulnya risiko dan mencegah terjadinya cedera yang disebabkan oleh kelelahan dalam mengambil tindakan atau tidak mengambil tindakan yang seharusnya dilakukan.

Rumah sakit sebagai tempat yang padat karya dengan berbagai prosedur, profesi, teknologi dan standar menjadi tempat yang paling rawan terhadap keselamatan pasien. Akibat insiden pada pasien dapat mengakibatkan cedera, membahayakan jiwa, perpanjangan rawat, bahkan kematian (Cahyono 2008).

\section{Insiden Keselamatan Pasien}

Institute of Medication mendefinisikan patient safety sebagai kejadian yang tidak diharapkan akibat dari melakukan atau tidak melakukan tindakan yang seharusnya dan bukan akibat dari penyakit maupun kondisi fisik pasien. Insiden keselamatan pasin merupakan akibat dari melakukan suatu tindakan (comission) atau tidak mengambil tindakan yang seharusnya diambil (omission) (Depkes RI, 2008).

Sementara pengertian insiden keselamatan pasien berdasarkan PMK RI Nomor 1691 tahun 2011 adalah setiap kejadian yang tidak disengaja dan kondisi yang mengakibatkan atau berpotensi mengakibatkan cedera yang dapat dicegah pada pasien, terdiri dari Kejadian Tidak Diharapkan, Kejadian Nyaris Cedera, Kejadian Tidak Cedera dan Kejadian Potensial Cedera. 
Jenis insiden keselamatan pasien berdasarkan Permenkes No. 1691 Tahun 2011 tentang Keselamatan Pasien, diantaranya adalah: 1) Kejadian Tidak Diharapkan (KTD) yaitu suatu kejadian cedera yang diakibatkan karena mengambil tindakan medis atau tidak mengambil tindakan medis yang seharusnya dilakukan, atau dengan kata lain bukan karena penyakit dasarnya atau kondisi pasien (Kohn, et al., 1999). Suatu kejadian yang tidak diharapkan yang mengakibatkan cedera pada pasien akibat melaksanakan suatu tindakan atau tidak mengambil tindakan yang seharusnya diambil, dan bukan karena penyakit dasarnya atau kondisi pasien. Kejadian tersebut dapat terjadi di semua tahapan dalam perawatan dari diagnosis, pengobatan dan pencegahan (Reason, 1998 dalam To Err Is Human: Building A Safer Health Sistem.); 2) Kejadian Nyaris Cedera (KNC) yaitu terjadinya insiden yang belum sampai terpapar ke pasien. Misalnya suatu obat dengan overdosis lethal akan diberikan, tetapi staf lain mengetahui dan membatalkannya sebelum obat diberikan kepada pasien; 3) Kejadian Tidak Cedera (KTC) yaitu suatu insiden yang sudah terpapar ke pasien, tetapi tidak mengakibatkan cedera; 4) Kejadian Potensial Cedera (KPC) yaitu kondisi yang sangat berpotensi untuk menimbulkan cedera, tetapi belum terjadi insiden. Misalnya obat LASA (Look Alike Sound Alike) disimpan berdekatan; 5) Kejadian Sentinel (KS) yaitu suatu Kejadian Tidak Diharapkan (KTD) yang mengakibatkan kematian atau cedera yang serius. Biasanya dipakai untuk kejadian yang sangat tidak diharapkan atau tidak dapat diterima seperti: operasi pada bagian tubuh yang salah. Pemilihan kata 'sentinel' terkait dengan keseriusan cedera yang terjadi (Misalkan amputasi pada kaki yang salah) sehingga pecarian fakta terhadap kejadian ini mengungkapkan adanya masalah yang serius pada kebijakan dan prosedur yang berlaku. (Permenkes No. 1691 Tahun 2011)

\section{Budaya Keselamatan Pasien}

Budaya keselamatan pasien adalah produk dari nilai, sikap, persepsi, kompetensi, dan pola perilaku dari individu dan kelompok dalam sebuah organisasi (pelayanan kesehatan) yang menentukan komitmen, gaya dan kemahiran dalam manajemen keselamatan pasien. Organisasi (pelayanan kesehatan) yang memiliki budaya keselamatan pasien yang cenderung positif dapat dilihat dari komunikasi saling percaya (mutual trust) antar komponen, dengan persepsi yang sama tentang pentingnya keselamatan, dan dengan keyakinan akan besarnya manfaat tindakan pencegahan (Agency for Healthcare Research and Quality, 2016).

Salah satu survey budaya keselamatan yang dikembangkan oleh Agency for Health Care Research and Quality (AHRQ) adalah The Hospital Survey on Patient Safety. Survey budaya keselamatan pasien tersebut terdiri dari 12 dimensi yang dikelompokkan menjadi 2 kelompok, yang dituangkan kedalam 9 bagian. Kelompok outcome (hasil) yang terdiri dari dua dimensi, yaitu sebagai berikut: a) keseluruhan persepsi tentang keselamatan pasien, b) frekuensi pelaporan kejadian/ insiden, merupakan jumlah nominal 
pelaporan insiden yang pernah dilaporkan yang diketahui oleh staf. Kelompok budaya keselamatan yang terdiri dari 10 dimensi, yaitu sebagai berikut: teamwork dalam unit, ekspektasi dan aksi pimpinan dalam mempromosikan keselamatan pasien, organizational learning, dukungan manajemen rumah sakit dalam keselamatan pasien, umpan balik dan komunikasi kejadian kesalahan, keterbukaan komunikasi, teamwork antar unit dalam rumah sakit, staffing, handoffs (serah terima) dan transisi dan respon tidak menyalahkan terhadap kejadian kesalahan.

Berdasarkan 12 dimensi yang terdapat dalam survey budaya keselamatan pasien menurut $A H R Q$, terdapat 1 dimensi yang dianggap penting yang dapat mempengaruhi terjadinya insiden keselamatan pasien. Dimensi tersebut adalah dimensi staffing.

\section{Staffing}

Sumber daya manusia adalah semua manusia yang terlibat di dalam suatu organisasi dalam mengupayakan terwujudnya tujuan organisasi tersebut (Hasibuan, 2012).

Prinsip yang direkomendasikan Institute Of Medicine dalam laporannya To Err Is Human (2000), untuk penerapan keselamatan pasien di rumah sakit adalah mendesain pekerjaan dengan memperhatikan faktor manusia dengan memperhitungkan jam kerja, beban kerja, staffing, ratio dan shift dengan memperhatikan faktor kelelahan, siklus tidur dan lainnya. Beban kerja perawat penting diketahui, karena asuhan keperawatan yang dilakukan perawat merupakan beban kerja utama perawat dan menjadi fokus dari semua aktifitas perawat dapat dilaksanakan dengan baik bila jumlah tenaga perawat tercukupkan.

Beban kerja yang ada pada perusahaan/organisasi sangat mempengaruhi hasil kinerja petugas. Stres kerja yang tinggi juga merupakan pengaruh pada petugas yang memegang ganda pekerjaan yang sebenarnya bukan bagian pekerjaannya sehingga karyawan pun menjadi tidak efektif pada melakukan kerja (Ahmad Ahid Mudayana, 2010).

Beban kerja yang dirasakan terlalu berat karena waktu kerja yang mendesak sehingga dilakukan secara terburu-buru, kualitas pengawasan yang rendah, iklim kerja yang tidak sehat, otoritas kerja yang tidak memadai yang berhubungan dengan tanggung jawab, konflik kerja, perbedaan nilai antar karyawan dengan pimpinan yang frustasi dalam kerja dapat menimbulkan stress kerja (Mangkunegara, 2005).

Berdasarkan teori di atas dapat disimpulkan bahwa untuk menerapkan keselamatan pasien di rumah sakit perlu memperhatikan faktor sumber daya manusia dengan memperhatikan jam kerja, beban kerja, shif, waktu kerja yang dapat berakibat pada stress kerja sehingga pelayanan menjadi tidak efektif.

\section{METODE}

Penelitian ini merupakan penelitian analitik observasional dengan pendekatan cross sectional karena pengumpulan data variabel hanya dalam satu periode waktu tertentu. Populasi dalam penelitian ini adalah staf medis dan non medis di unit kerja pelayanan RSU Haji Surabaya. Sampel 
diambil dengan menghitung dari keseluruhan populasi yaitu dari 42 unit kerja pelayanan disampling menjadi 38 unit kerja pelayanan dengan menggunakan rumus Slovin. Sampel 38 unit kerja pelayanan kemudian dihitung kembali dengan jumlah populasi responden berdasarkan jumlah staf medis dan non medis di setiap unit kerja dan didapatkan total populasi responden sebanyak 663. Populasi responden sebanyak 663 responden kemudian dilakukan sampling menjadi 249 sampel. 249 sampel akan dihitung proporsrinya berdasarkan jumlah staf medis dan non medis disetiap unit kerja pelayanan.

Data penelitian ini berupa data sekunder dan data primer. Data sekunder merupakan data insiden keselamatan pasien pada tahun 2016 yang didapatkan dari pemegang program keselamatan pasien RSU Haji Surabaya. Data primer diperoleh dengan cara melakukan pengisian kuesioner dimensi staffing dengan 4 pertanyaan. Alokasi waktu untuk pengisian kuesioner adalah \pm 15 menit. Selanjutnya, dilakukan analisa data dengan mengetahui tingkat dimensi staffing terlebih dahulu.

Pengolahan data dan peneliti dilakukan dengan pengklasifikasian data yaitu membagi jawaban dari responden pada setiap pernyataan dalam dimensi staffing menjadi 2 kategori, yaitu respon positif dan respon negatif. Respon positif adalah jawaban responden berupa setuju/sering dan sangat setuju/selalu pada pernyataan positif dan jawaban negatif berupa tidak setuju/jarang dan sangat tidak setuju/tidak pernah pada pernyataan negatif. Respon negatif yang merupakan kebalikan dari respon positif adalah jawaban responden berupa setuju/sering dan sangat setuju/selalu pada pernyataan negatif dan jawaban tidak setuju/jarang dan sangat tidak setuju/tidak pernah pada pernyataan positif.

Dimensi staffing diklasifikasikan menjadi 3 kategori berdasarkan pedoman pada Hospital Survey On Patient Safety Culture yang dilakukan AHRQ pada tahun 2016. Dimensi staffing dikatakan kuat apabila respon positiif sebesar sama dengan $75 \%$ atau lebih, dikatakan sedang apabila respon positif sebesar $50 \%$ - $75 \%$ dan dikatakan lemah apabila respon positif kurang dari $50 \%$.

\section{HASIL DAN PEMBAHASAN}

\section{Karakteristik Responden}

Berikut merupakan tabel karakteristik staf medis dan non medis di unit kerja pelayanan RSU Haji Surabaya berdasarkan pendidikan dan masa kerja:

Tabel 2. Pendidikan Terakhir Staf Medis dan Non Medis di Unit Kerja Pelayanan RSU Haji Surabaya Tahun 2016

\begin{tabular}{lrr}
\hline \multicolumn{1}{c}{ Pendidikan Terakhir } & $\begin{array}{c}\text { Jumlah } \\
\text { (n) }\end{array}$ & $\begin{array}{c}\text { Persentase } \\
\text { (\%) }\end{array}$ \\
\hline Diploma & 152 & 61 \\
Sarjana (S1/Profesi) & 58 & 23,3 \\
Master (S2) & 27 & 10,8 \\
Lain-lain (SMA/SMK) & 12 & 4,8 \\
\hline \multicolumn{1}{c}{ Total } & 249 & 100 \\
\hline
\end{tabular}

Tabel 3. Masa Kerja Staf Medis dan Non Medis di Unit Kerja Pelayanan RSU Haji Surabaya Tahun 2016

\begin{tabular}{lrr}
\hline $\begin{array}{c}\text { Masa Kerja } \\
\text { di RSU Haji } \\
\text { Surabaya }\end{array}$ & $\begin{array}{c}\text { Jumlah } \\
\text { (n) }\end{array}$ & \multicolumn{2}{c}{$\begin{array}{c}\text { Persentase } \\
\text { (\%) }\end{array}$} \\
\hline$<1$ Tahun & 5 & 2 \\
\hline $1-5$ Tahun & 54 & 21,7 \\
\hline $6-15$ Tahun & 95 & 38,2 \\
\hline$>15$ Tahun & 95 & 38,2 \\
\hline Total & 249 & 100 \\
\hline
\end{tabular}


Berdasarkan tabel 2 telah disimpulkan bahwa sebagian besar (61\%) staf medis dan non medis di unit kerja pelayanan RSU Haji Surabaya dan sebagian kecil berpendidikan SMA/SMK (4,8\%).

Tabel 3 menunjukkan bahwa staf medis dan non medis di unit kerja pelayanan mempunyai masa kerja di RSU Haji Surabaya sebagian besar selama $6-15$ tahun dan $>15$ tahun $(38,2 \%)$ dan sebagian kecil $<1$ tahun $(2 \%)$.

Hasil penelitian selanjutnya adalah dimensi staffing. Dimensi staffing yang dimaksud adalah proses penataan staf dalam unit untuk menangani beban kerja dan jam kerja yang sesuai untuk memberikan pelayanan yang baik bagi pasien. Adapun indikator penilaian dari dimensi staffing, adalah: 1) jumlah staf yang cukup untuk menyelesaikan beban kerja di unit, 2) tidak ada bekerja lembur untuk menangani pasien, 3) menggunakan tenaga honorer untuk menangani pasien, 4) melakukan pekerjaan secara terburuburu untuk melayani pasien.

Tabel 4 adalah tabel hasil penelitian mengenai dimensi staffing di 38 unit kerja pelayanan RSU Haji Surabaya yang diwakili dari setiap responden yang terdapat di unit.

Tabel 4. Dimensi Staffing di Unit Kerja Pelayanan RSU Haji Surabaya Tahun 2016

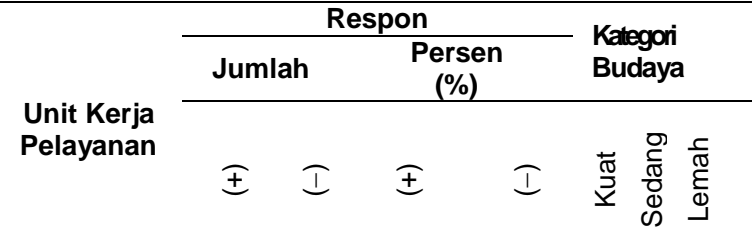

\begin{tabular}{lllrrll}
\hline SMF Syrf & 7 & 1 & 87,5 & 12,5 & $\mathrm{~K}$ \\
\hline SMF Radi & 7 & 1 & 87,5 & 12,5 & $\mathrm{~K}$ \\
\hline SMF PD & 9 & 3 & 75 & 25 & $\mathrm{~K}$ \\
\hline SMF Paru & 7 & 1 & 87,5 & 12,5 & $\mathrm{~K}$ \\
\hline SMF Obgy & 9 & 3 & 75 & 25 & $\mathrm{~K}$ \\
\hline SMF Mata & 8 & 0 & 100 & 0 & $\mathrm{~K}$ \\
\hline SMF KK & 8 & 0 & 100 & 0 & $\mathrm{~K}$ \\
\hline
\end{tabular}

\begin{tabular}{|c|c|c|c|c|c|c|c|}
\hline \multirow{3}{*}{$\begin{array}{l}\text { Unit Kerja } \\
\text { Pelayanan }\end{array}$} & \multicolumn{4}{|c|}{ Respon } & \multirow{2}{*}{\multicolumn{3}{|c|}{$\begin{array}{l}\text { Kategori } \\
\text { Budaya }\end{array}$}} \\
\hline & \multicolumn{2}{|c|}{ Jumlah } & \multicolumn{2}{|c|}{$\begin{array}{c}\text { Persen } \\
\text { (\%) }\end{array}$} & & & \\
\hline & 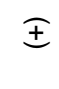 & I & \pm & I & $\stackrel{+}{\frac{\pi}{\partial}}$ & 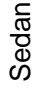 & 䆖 \\
\hline SMF Jiwa & 4 & 0 & 100 & 0 & $\mathrm{~K}$ & & \\
\hline SMF Jt & 7 & 5 & 58,33 & 41,67 & & $\mathrm{~S}$ & \\
\hline SMF Bd & 9 & 3 & 75 & 25 & $\mathrm{~K}$ & & \\
\hline SMF Anak & 7 & 5 & 58,33 & 41,67 & & $\mathrm{~S}$ & \\
\hline SMF RM & 4 & 4 & 50 & 50 & & $S$ & \\
\hline SMF PK & 2 & 2 & 50 & 50 & & $\mathrm{~S}$ & \\
\hline SMF PA & 2 & 2 & 50 & 50 & & $\mathrm{~S}$ & \\
\hline SMF ICU & 4 & 4 & 50 & 50 & & $\mathrm{~S}$ & \\
\hline SMF IGD & 15 & 1 & 93,75 & 6,25 & $\mathrm{~K}$ & & \\
\hline SMF Gigi & 15 & 1 & 93,75 & 625 & $\mathrm{~K}$ & & \\
\hline Psikolog & 2 & 2 & 50 & 50 & & $\mathrm{~S}$ & \\
\hline Apoteker & 8 & 12 & 40 & 60 & & & $\mathrm{~L}$ \\
\hline IRJA & 50 & 18 & 73,53 & 26,47 & & $\mathrm{~S}$ & \\
\hline IRNA & 103 & 89 & 53,65 & 46,35 & & $\mathrm{~S}$ & \\
\hline Radiologi & 19 & 17 & 52,78 & 47,22 & & $\mathrm{~S}$ & \\
\hline GNA & 52 & 39 & 57,61 & 42,39 & & $\mathrm{~S}$ & \\
\hline PK & 44 & 8 & 84,62 & 15,38 & $\mathrm{~K}$ & & \\
\hline PA & 4 & 4 & 50 & 50 & & $\mathrm{~S}$ & \\
\hline ICU & 32 & 8 & 80 & 20 & $\mathrm{~K}$ & & \\
\hline ICCU & 9 & 11 & 45 & 55 & & & $\mathrm{~L}$ \\
\hline $\mathrm{NICU}$ & 10 & 10 & 50 & 50 & & $\mathrm{~S}$ & \\
\hline R. Jantung & 15 & 5 & 75 & 25 & $\mathrm{~K}$ & & \\
\hline IGD Amb & 7 & 1 & 87,5 & 12,5 & $\mathrm{~K}$ & & \\
\hline VK & 21 & 7 & 75 & 25 & $\mathrm{~K}$ & & \\
\hline $\mathrm{Hd}$ & 18 & 6 & 75 & 25 & $\mathrm{~K}$ & & \\
\hline Gizi & 39 & 5 & 88,64 & 11,36 & $\mathrm{~K}$ & & \\
\hline GILUT & 6 & 6 & 50 & 50 & & $\mathrm{~S}$ & \\
\hline Farmasi & 41 & 47 & 46,59 & 53,41 & & & $\mathrm{~L}$ \\
\hline Binroh & 2 & 2 & 50 & 50 & & $\mathrm{~S}$ & \\
\hline IBS & 19 & 17 & 52,78 & 47,22 & & $\mathrm{~S}$ & \\
\hline Anastesi & 9 & 11 & 45 & 55 & & & $\mathrm{~L}$ \\
\hline & & tal & & & $\stackrel{\infty}{\leftarrow}$ & $\stackrel{\varphi}{\leftarrow}$ & $\theta$ \\
\hline & & $\begin{array}{l}\text { sen } \\
\text { \%) }\end{array}$ & & & $\stackrel{\mathscr{P}}{\mathscr{q}}$ & $\frac{\check{\tau}}{\text { ชั }}$ & חొ \\
\hline
\end{tabular}

Berdasarkan tabel 4 dapat diketahui bahwa dimensi staffing di unit kerja pelayanan RSU Haji Surabaya berkategori kuat pada 18 unit $(47,36 \%)$ dengan respon positif $\geq 75 \%$, contohnya pada unit SMF syaraf, SMF radiologi, SMF penyakit dalam dan SMF obstetri dan ginekologi yang mempunyai arti bahwa pada 18 unit mempunyai jumlah staf cukup untuk menyelesaikan beban kerja tanpa bekerja lembur sehingga pekerjaan tidak dilakukan secara terburu-buru. Berkategori dimensi staffing sedang pada 16 unit $(42,11 \%)$ dengan respon positif berada di antara $50 \%$ - 75\% contohnya 
adalah rawat jalan, radiologi, graha nur afiyah dan bedah sentral. Berkategori lemah pada 4 unit $(10,56 \%)$ yaitu ICCU, farmasi, apoteker dan anastesi yang menunjukkan bahwa jumlah staf medis dan non medis tidak memenuhi untuk menyelesaikan beban kerja yang tinggi, harus bekerja lembur, menggunakan tenaga kerja honorer dan masih melakukan pekerjaan secara terburuburu untuk melayani pasien. Hal tersebut dapat memicu terjadinya insiden keselamatan pasien.

Hal yang sama juga disampaikan Griffiths et all (2008), yang menyatakan bahwa faktor yang berpengaruh dalam risiko terjadinya infeksi di rumah sakit salah satunya yaitu beban kerja yang tidak sesuai dengan staf yang tersedia. KTD bisa terjadi dikarenakan oleh beberapa masalah. Masalah tersebut yakni masalah sumber daya manusia, kebijakan, prosedur yang tidak adekuat dan kegagalan teknis (AHRQ, 2003). Manajemen sumber daya manusia yang tepat baik dalam kualitas akan kuantitas dapat mencegah terjadinya insiden keselamatan pasien.

\section{Insiden Keselamatan Pasien}

Menurut Peraturan Menteri Kesehatan Republik Indonesia Nomor 1691 Tahun 2011 tentang Keselamatan Pasien insiden keselamatan pasien di bedakan menjadi 5 jenis, yaitu: kejadian tidak diharapkan (KTD), kejadian nyaris cedera (KNC), kejadian tidak cedera (KTC), kejadian potensial cedera (KPC) dan kejadian sentinel (KS).

Berikut adalah insiden keselamatan pasien yang terjadi di unit kerja pelayanan RSU Haji Surabaya berdasarkan Laporan Insiden Keselamatan Pasien RSU Haji Surabaya mulai

bulan Januari - Oktober 2016 akan disajikan pada tabel 5.

Berdasarkan tabel 5 dapat diketahui bahwa terjadi 22 insiden keselamatan pasien di unit kerja pelayanan RSU Haji Surabaya. Sebagian besar $(63,64 \%)$ insiden keselamatan pasien terjadi pada jenis insiden kejadian tidak cidera (KTC), disusul dengan jenis kejadian tidak diharapkan (KTD) $(22,73 \%)$ dan paling sedikit pada jenis kejadian nyaris cedera (KNC) yaitu (13,64\%). Dilihat berdasarkan tempat terjadi insiden keselamatan pasien, dengan urutan insiden paling banyak terjadi pada unit kerja pelayanan rawat inap dengan jumlah 6 insiden, ICCU dengan jumlah 4 insiden, bedah sentral 3 insiden, radiologi; pathologi klinik; gizi dengan jumlah 2 insiden dan rawat jalan; graha nur afiyah; ICU dengan jumlah 1 insiden. Dan terdapat unit yang tidak terjadi insiden keselamatan pasien (0) contohnya seperti: SMF syaraf, SMF radiologi, SMF penyakit dalam, dan NICU.

Tabel 5. Insiden Keselamatan Pasien di Unit Kerja Pelayanan RSU Haji Surabaya Bulan Januari - Oktober Tahun 2016

\begin{tabular}{|c|c|c|c|c|c|c|}
\hline \multirow{2}{*}{$\begin{array}{l}\text { Unit Kerja } \\
\text { Pelayanan }\end{array}$} & \multicolumn{5}{|c|}{$\begin{array}{c}\text { Insiden } \\
\text { Keselamatan Pasien }\end{array}$} & \multirow[b]{2}{*}{ Total } \\
\hline & $\stackrel{\varrho}{E}$ & $\stackrel{\circlearrowright}{Z}$ & $\stackrel{\cup}{\underline{E}}$ & $\begin{array}{l}0 \\
\underline{n}\end{array}$ & $\underline{\mathscr{C}}$ & \\
\hline IRJA & 0 & 0 & 1 & 0 & 0 & 1 \\
\hline IRNA & 2 & 0 & 4 & 0 & 0 & 6 \\
\hline Radiologi & 0 & 1 & 1 & 0 & 0 & 2 \\
\hline GNA & 0 & 0 & 1 & 0 & 0 & 1 \\
\hline $\mathrm{PK}$ & 0 & 1 & 1 & 0 & 0 & 2 \\
\hline ICU & 0 & 0 & 1 & 0 & 0 & 1 \\
\hline ICCU & 1 & 1 & 2 & 0 & 0 & 4 \\
\hline Gizi & 1 & 0 & 1 & 0 & 0 & 2 \\
\hline IBS & 1 & 0 & 2 & 0 & 0 & 3 \\
\hline Total & 5 & 3 & 14 & 0 & 0 & 22 \\
\hline $\begin{array}{c}\text { Persentase } \\
\text { (\%) }\end{array}$ & $\underset{N}{N}$ & ஸ్ & छ్ర & 0 & 0 & 용 \\
\hline
\end{tabular}


Depkes, (2008) mengungkapkan bahwa faktor yang berkontribusi terhadap terjadinya insiden keselamatan pasien adalah: faktor eksternal/luar rumah sakit, faktor organisasi dan manajemen, faktor lingkungan kerja, faktor tim, faktor petugas dan kinerja, faktor tugas, faktor pasien, dan faktor komunikasi.

Agency for Healthcare Research and Quality/AHRQ (2016) mengatakan bahwa faktor yang dapat menimbulkan insiden keselamatan pasien adalah : komunikasi, arus informasi yang tidak adekuat, masalah SDM, hal yang berhubungan dengan pasien, transfer pengetahuan di rumah sakit, alur kerja, kegagalan teknis, kebijakan dan prosedur yang tidak adekuat.

\section{Pengaruh Dimensi Staffing Terhadap Insiden Keselamatan Pasien}

Berdasarkan hasil penelitian dapat diperoleh distribusi insiden keselamatan pasien berdasarkan dimensi staffing. Berikut adalah tabulasi silang distribusi insiden keselamatan pasien berdasarkan dimensi staffing yang akan disajikan pada tabel 6 .

Berdasarkan tabel 6 dapat diketahui bahwa unit kerja pelayanan dengan dimensi staffing berkategori kuat terdapat $3 \quad(16,7 \%)$ insiden keselamatan pasien dengan frekuensi jarang (1-3), unit tersebut adalah pathologi klinik, ICU dan gizi. Untuk unit kerja pelayanan dimensi staffing berkategori sedang terjadi 4 (25\%) insiden keselamatan pasien dengan frekuensi jarang $(1-3)$ yaitu rawat jalan, radiologi, graha nur afiyah dan bedah sentral dan 1 $(6,2 \%)$ insiden keselamatan pasien dengan frekuensi sering (> 3) yaitu ICCU. Dan pada unit dengan dimensi staffing berkategori lemah terdapat 1 (25\%) insiden dengan frekuensi sering (>3) yaitu pada unit rawat inap.

Tabel 6. Tabulasi Silang Antara Budaya Keselamatan Pasien berdasarkan Dimensi Staffing Dengan Insiden Keselamatan Pasien di Unit Kerja Pelayanan RSU Haji Surabaya

\begin{tabular}{|c|c|c|c|c|c|c|c|c|}
\hline \multirow{3}{*}{$\begin{array}{c}\begin{array}{c}\text { Variab } \\
\text { el }\end{array} \\
\text { BKP } \\
\end{array}$} & \multicolumn{6}{|c|}{$\begin{array}{c}\text { Insiden Keselamatan } \\
\text { Pasien }\end{array}$} & \multirow{2}{*}{\multicolumn{2}{|c|}{ Total }} \\
\hline & \multicolumn{2}{|c|}{ 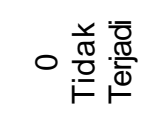 } & \multicolumn{2}{|c|}{ 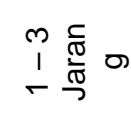 } & \multicolumn{2}{|c|}{ 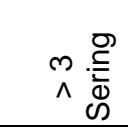 } & & \\
\hline & $\mathrm{n}$ & $\%$ & $\mathrm{n}$ & $\%$ & $\mathrm{n}$ & $\%$ & $n$ & $\%$ \\
\hline Kuat & 15 & 83,3 & 3 & 16,7 & 0 & 0 & 18 & 100 \\
\hline Sedang & 11 & 68,8 & 4 & 25 & 1 & 6,2 & 16 & 100 \\
\hline Lemah & 3 & 75 & 0 & 0 & 1 & 25 & 4 & 100 \\
\hline Total & 29 & 76,3 & 7 & 18,4 & 2 & 5,3 & 38 & 100 \\
\hline
\end{tabular}

Hasil tabulasi silang menunjukkan bahwa terjadi penurunan insiden keselamatan pasien frekuensi sering yang bermakna pada unit berkategori lemah dan unit berkategor sedang. Penurunan yang bermakna juga terjadi pada insiden keselamatan pasien frekuensi jarang di unit kategori sedang dan di unit berkategori kuat. Perbedaan jumlah unit yang terjadi insiden dengan unit yang tidak terjadi insiden belum mencukupi untuk dilakukannya uji secara statistika sehingga diperoleh hasil tidak ada pengaruh yang signifikan antara dimensi staffing dengan insiden keselamatan pasien di unit kerja pelayanan RSU Haji Surabaya dengan nilai signifikansi 0,192.

Faktor kontribusi yang mempengaruhi terjadinya kejadian tidak diiharapkan (KTD) yaitu (1) organisasi dan manajemen: kepemimpinan dan komitmen terhadap keselamatan pasien lemah, penempatan staf mutu/safety belum ada, dukungan finasial untuk mendukung kebijakan mutu tidak memadai. (2) lingkungan kerja: lingkungan kerja 
yang bersifat menyalahkan, motivasi kerja, beban kerja berlebihan, pengaturan pergantian pengaturan jaga tidak berjalan, jumlah staf yang kurang, banyak interupsi dalam bekerja, tekanan waktu dan psikologis (3) team work: komunikasi kurang terbina dengan baik, supervisi tidak berjalan (4) faktor individu: pengetahuan, keterampilan, sikap dan prilaku, kondisi fisik dan mental (5) faktor tugas: ketersediaan Standard Operational Procedure belum ada petunjuk, pedoman (guideline).

Peningkatan insiden keselamatan pasien frekuensi sering yang signifikan pada unit berkategori sedang ke unit berkategori lemah dan penurunan insiden keselamatan pasien frekuensi jarang yang signifikan pada unit berkategori budaya sedang ke unit berkategori kuat menunjukkan bahwa jumlah staf ikut berperan untuk terjadinya insiden keselamatan pasien. Hal tersebut sejalan dengan pernyataan yang menyatakan bahwa beban kerja yang terlalu tinggi dapat sebagai penyebab kegagalan aktif (active failure) yang ikut berkontribusi terhadap terjadinya insiden keselamatan pasien di rumah sakit (NPSA, 2012). Hal tersebut disebabkan karena beban kerja yang terlalu berlebihan akan menimbulkan berbagai efek yakni kelelahan baik fisik maupun mental dan reaksi emosional seperti sakit kepala, gangguan pencernaan, kelalaian, lupa dan mudah marah sehingga secara potensial membahayakan pekerja atau perawat (Manuaba, 2000).

llyas (2011) berpendapat bahwa SDM merupakan kunci yang sangat penting untuk kemajuan dan keberhasilan organisasi, maka kualitas dan kuantitas SDM rumah sakit harus direncanakan dengan baik. Kekurangan ketenagaan yang tidak segera diatasi menambah kemungkinan besar terjadinya insiden keselamatan pasien yang berulang.

Beban kerja yang terlalu berlebihan akan menimbulkan berbagai efek yakni kelelahan baik fisik maupun mental dan reaksi emosional seperti sakit kepala, gangguan pencernaan, kelalaian, lupa dan mudah marah sehingga secara potensial membahayakan pekerja atau perawat (Manuaba, 2000).

Banyaknya tugas tambahan yang harus dikerjakan oleh perawat dapat menganggu penampilan kerja dari perawat. Akibat negatif dari banyaknya tugas tambahan perawat diantaranya timbulnya emosi perawat yang tidak sesuai dengan yang diharapkan dan berdampak buruk bagi produktifitas perawat (Irwady, 2007). Beban kerja yang terlalu tinggi akan menyebabkan seorang perawat stess, dampak buruk yang dapat ditimbulkan jika seorang perawat mengalami stress ialah dapat mengganggu interaksi sosialnya, baik itu dengan rekan kerja, dokter maupun pasien. Efektivitas kerja dapat pula menjadi terganggu, karena pada umumnya apabila seseorang mengalami stres, maka akan terjadi gangguan baik itu pada psikologisnya maupun keadaan fisiologisnya (Anil JC, 2010). Berbagai teori yang tersebut di atas dapat disimpulkan bahwa staf medis dan non medis yang terdapat di unit kerja pelayanan RSU Haji Surabaya harus sesuai dengan beban kerja yang diterima karena apabila jumlah staf medis dan non medis tidak dapat memenuhi beban kerja maka staf medis dan non medis akan 
mengalami stress kerja dan kelelahan sehingga memicu terjadinya insiden keselamatan pasien.

Insiden keselamatan pasien terjadi karena beberapa faktor yang membentuk sistem, apabila salah satu faktor yang dapat memepengaruhi insiden keselamatan pasien belum terpenuhi maka belum dapat dipastian bahwa insiden keselamatan pasien tidak terjadi secara berulang. Penerapan budaya keselamatan pasien dikatakan berhasil apabila semua elemen yang ada di dalam rumah sakit menerapkan budaya keselamatan pasien dalam pekerjaannya sehari-hari (Hudson, 1999; Reilling, 2006).

\section{SIMPULAN}

Berdasarkan hasil penelitian dapat disimpulkan bahwa: (1) dimensi staffing di unit kerja pelayanan RSU Haji Surabaya berkategori kuat pada 18 unit dengan respon positif $\geq 75 \%$, sedang pada 16 unit dengan respon positif berada di antara $50 \%-75 \%$ dan lemah pada 4 unit (2) terjadi 22 insiden keselamatan pasien di unit kerja pelayanan RSU Haji Surabaya dalam periode waktu bulan januari - Oktober 2016. Dengan sebagian besar $(63,64 \%)$ jenis insiden KTC, $22,73 \%$ insiden jenis KTD dan 13,64\% insiden jenis KNC (3) unit kerja pelayanan berkategori kuat terjadi 3 insiden dengan frekuensi jarang $(1-3)$, unit kerja pelayanan berkategori sedang terjadi 4 insiden dengan frekuensi jarang $(1-3)$ dan 1 insiden dengan frekuensi sering (> 3), sedangkan pada unit kerja pelayanan berkategori lemah terjadi 1 insiden dengan frekuensi sering (> 3), (4) hasil uji regresi linier sederhana menunjukkan tidak ada pengaruh signifikan antara dimensi staffing terhadap insiden keselamatan pasien.

Berdasarkan hasil penelitian, maka saran yang dapat direkomendasikan adalah: 1) perlu dilakukan perencanaan kebutuhan tenaga kerja dengan menggunakan metode WISN

pada unit kerja dengan dimensi berkategori lemah yaitu pada unit ICCU, farmasi, apoteker dan anastesi 2) mempertimbangkan SDM baik secara kuantitatif dengan menambah jumlah staf medis atau non medis disesuaikan dengan jumlah kunjungan pasien dan pelayanan yang diberikan di unit kerja pelayanan. Segi kulaitatif dapat dilakukan pelatihan mengenai manajemen stress.

\section{DAFTAR PUSTAKA}

Agency for Healthcare Research and Quality. 2003. Patient safety culture surveys. http://www.ahrq.gov/qual/pattientsafetycultur e. Quality (AHRQ) Diperoleh 14 Juni 2016

Agency for Healthcare Research and Quality. 2016. Patient safety culture surveys. http://www.ahrq.gov/qual/pattientsafetycultur e. Quality (AHRQ) tahun 2016. Diperoleh 14 Juni 2016

Ahmad Ahid Mudayana. 2010. Hubungan Beban Kinerja Dengan Kinerja Karyawan Di Rumah Sakit Nur Hidayah Bantul. Kes Mas Vol. 6 No 1 Issn 1978-0575

Anil ,JC. (2010). Hubungan beban kerja perawat dengan stres kerja di instalasi rawat inap RSU Islam Surakarta: Universitas Muhammadiyah Surakarta

Cahyono, SB 2008, Membangun Budaya Keselamatan Pasien dalam Praktik Kedokteran, Kanisius, Yoyakarta

Cooper, M. D. 2000. Towards a model of safety culture. Safety Science, 36 (2), 111-136

Depkes RI, 2008, Panduan Nasional Keselamatan Pasien Rumah Sakit (Patient Safety). Departemen Kesehatan Republik Indonesia, Jakarta

Gomes, Faustino Cardoso. 2003. Manajemen Sumber Daya Manusia. Andi, Yogyakarta

Griffiths P, Renz A, Hughes J, Rafferty AM. 2008. Impact of Organisation and Management Factors on Infection Control in Hospital: a Scoping Review. http://www.ncbi.nlm.nih.gov/m/pubmed/1964 7338 Diperoleh 29 Desember 2016 
Hasibuan, M. S. P., 2012. Manajemen Sumber Daya Manusia. Jakarta: Bumi Aksara

Hudson, P. 1999. Safety culture theory and practice. http://www.ftp.rta.nato.int/public/PubFulltext/ RTO/MP/RTO-MP-032///MP-032-08.pdf, diperoleh 27 Juli 2016

Hughes, R.G. 2008. Patient Safety and Quality an Evidence Based Handbook of Nurses. Rockville MD: Agency for Healthcare Research and Quality Publications, diakses 18 Juni 2016, http://www.ahrg.gov/QUAL/nursehdbk.

Institute of Medicine. 2000. To Err In Human: Building a Safer Health System (Washington: National Academy Press.

Ilyas, Y. 2011. Perencanaan SDM Rumah Sakit, Teori, Metoda dan Formula. FKM-UI: Jakarta.

Irwadi, (2007). http:// Irwadykapanlawi. Wordppress.Com/2007/10/28

Institute of medicine. 2000. Err In Human: Building a Safer Health System. Kohn, LT. Corrigan, J.M Donaldson, M.S (Ed). Washington DC: National academy Press.

Komite Keselamatan Pasien Rumah Sakit. 2008. Pedoman Pelaporan Insiden Keselamatan Pasien (Patient Safety Incident Report). Jakarta : Edisi 2

Kohn L T., J.M. Corrigan., M.S. Donaldson, eds., To Err In Human: Building a Safer Health System (Washington: National Academies Press, 1999)

Mangkunegara. 2005. Manajemen Sumber Daya Manusia Perusahaan. Bandung: PT. Remaja Rosdakarya
Manuaba, A. 2000. Ergonomi, Kesehatan Keselamatan Kerja. Dalam Wygnyosoebroto.S Dan Wiranto.S.E."Eds, Proceeding Seminar Nasional Ergonomi PT. Guna Widya. Surabaya

National Patient Safety Agency (NPSA). 2012. http://www.gov.npsa.nsh.uk, diperoleh 29 Desember 2016

Nawawi, Hadari. 2011. Manajemen Sumber Daya Manusia Untuk Bisnis Yang Kompetitif. Yogyakarta. Gajah Mada University Press.

PERMENKES RI No 1691. 2011. Keselamatan Pasien Rumah Sakit. Menteri Kesehatan Republik Indonesia

Reason, J. 1998. Archieving a safe culture: Theory and practice. Work \% Stress, 12 (3), 293306 , http://amlsafety.com.au/AMLstores/ images/pdffiles/21may09-JReason.pdf Diperoleh 14 Juni 2016

Reilling, J. G. (2006). Creating a culture of patient safety through innovative hospital design. Journal Advanced in Patient Safety, 2(20), 115.

Setiowati, D. 2010. Hubungan Kepemimpinan Efektif Head Nurse dengan Penerapan Budaya Keselamatan Pasien oleh Perawat Pelaksana di RSUPN Dr. Cipto Mangkusumo Jakarta. Tesis, Universitas Indonesia: Jakarta. 